\title{
Combined use of FORMOSAT-2 images with a crop model for biomass and water monitoring of permanent grassland in Mediterranean region
}

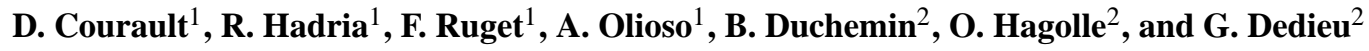 \\ ${ }^{1}$ INRA, National Institute for Agricultural Research, UMR 1114 EMMAH, Domaine St. Paul, 84914, Avignon, France \\ ${ }^{2}$ CESBIO, BPI 811, 18 Avenue E. Belin, 31401 Toulouse Cedex 9, France
}

Received: 16 April 2010 - Published in Hydrol. Earth Syst. Sci. Discuss.: 22 June 2010

Revised: 26 August 2010 - Accepted: 27 August 2010 - Published: 9 September 2010

\begin{abstract}
The aim of this study is to propose methods to improve crop and water management in Mediterranean regions. At landscape scale, there is a spatial variability of agricultural practices, particularly for grasslands irrigated by flooding. These grasslands are harvested three times per year and produce high quality hay, but their productions decreased significantly during the last few years because of the water scarcity. It is therefore important to assess the real water requirement for crops in order to predict productions in the case of agricultural practice modifications. Until now, the spatial variability of agricultural practices was obtained through surveys from farmers, but this method was tedious to describe an entire region. Thus, the specific aim of the study is to develop and assess a new method based on a crop model for estimating water balance and crop yield constrained by products derived from optical remote sensing data with high spatio-temporal resolution.
\end{abstract}

A methodology, based on the combined use of FORMOSAT-2 images and the STICS crop model, was developed to estimate production, evapotranspiration and drainage of irrigated grasslands in "the Crau" region in the South Eastern France. Numerous surveys and ground measurements were performed during an experiment conducted in 2006. Simple algorithms were developed to retrieve the dynamic of Leaf Area Index (LAI) for each plot and the main agricultural practices such as mowing and irrigation dates. These variables computed from remote sensing were then used to parameterize STICS, applied at region scale to estimate the spatial variability of water budget associated with the biomass productions. Results are displayed at the farm

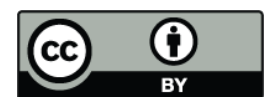

Correspondence to: D. Courault (courault@avignon.inra.fr) scale. Satisfactory results were obtained when compared to ground measurements. The method for the extrapolation to other regions or crops is discussed as regard to data available.

\section{Introduction}

Accurate information on water consumption for irrigation of the farms has long been a critical need in water resources management. In the context of the global change, this point is becoming crucial, as it is necessary to develop agricultural practices that reduces water consumption and also maintains both ecosystem diversity and good productions. During these last years, the farmers tended to adapt their farming practices to minimize the effects of severe weather conditions on their crops, such as drought. According to the region and to the water availability, they could for example use more water and fertilizers to maintain acceptable production levels. However, such behaviors are not possible everywhere, and can lead to negative effects on environment (water reserve exhausted, pollution...). It is thus important to develop methods to predict the impact of agricultural practice changes both on production and environment and also improve our knowledge on water cycle at different scales in space and time.

Mediterranean region is particularly sensitive to changes in agricultural practices and land use since it is often subject to extremes climatic hazards (Evans, 2009; Todisco and Vergni, 2008). During these last years, severe drought conditions have reduced the stocks of water and thus have pushed the policymakers to restrict irrigation in some areas, such as in the Crau region, located in the South-Eastern France (Fig. 1). About half of this region is devoted to agricul-

Published by Copernicus Publications on behalf of the European Geosciences Union. 


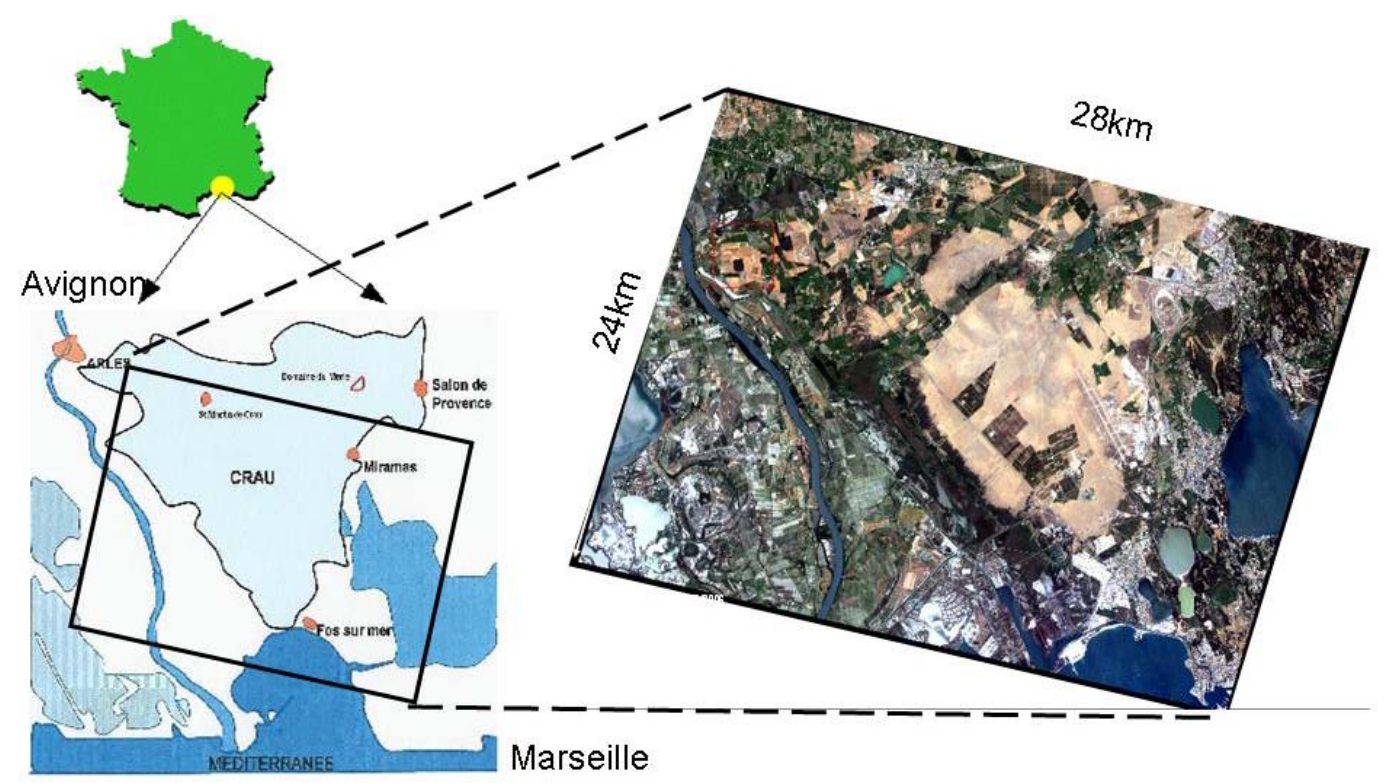

Fig. 1. Location of the studied area, and the footprint of the FORMOSAT-2 image.

ture, with permanent irrigated grasslands representing $67 \%$ of the usable agricultural area (Mérot et al., 2006a). These grasslands are irrigated by flooding, harvested three times per year and produce a high quality hay exported all over the word (http://www.foindecrau.com). Generally, farmers bring more water than that needed by the crop $\left(15000 \mathrm{~m}^{3} / \mathrm{ha} /\right.$ year to $24000 \mathrm{~m}^{3} /$ ha/year), and more than $60 \%$ of this water participates to the ground-table recharge used for urban and industrial sectors (Mérot et al., 2008a). The water restrictions applied during the last dry years, affected seriously hay production in terms of yield (loss of $30 \%$ observed in 2005), and agricultural practices calendar. It is thus important to estimate accurately water needs for irrigated crops to better evaluate the future consequences of climate changes for both agricultural practices and crop production. The scientific community is increasingly concerned to develop methods in order to increase the water use efficiency and predict yields.

Over the years, scientists have proposed tools such as crop models to simulate the crop behaviour under various environmental conditions (Brisson et al., 1998; Duru et al., 2009; Schapendonk et al., 1998). A lot of models were thus proposed in literature ranging from complex approaches simulating growth for different crops such as CERES (Jones et al., 2003), WOFOST (Pogacar and Kajfez-Bogataj, 2009), STICS (Brisson et al., 2003) up to whole farm optimization models such as GRAZEGRO (Barrett et al., 2005), MODERATO (Bergez et al., 2002). Modeling of grassland requires to define growth functions quite different compared with those representing cereal development. Indeed, grassland growth is generally very quick in Mediterranean region, mainly because of the huge water amount brought by flood- ing irrigation and favorable meteorological conditions. Three harvests are made between May and September. Some crop models propose a generic approach where the plant development (representing mainly by the Leaf Area Index, LAI), is modelled with functions depending on temperature, photoperiod and chilling needs (Ruget et al., 2009). Other approaches propose combining decision models and a biophysical models to take into account the response to irrigation (Mailhol and Mérot, 2008). Though all the previous mentioned approaches give quite satisfactory results at field scale, issues still exist in applying these models at larger scales. Indeed it is often tedious and difficult to define some key parameters describing the agricultural practices at regional scale, because of their very wide spatial variability. Some approaches proposed classifications to define the main agricultural practices performed in a given region. For example, in the ISOP system (Information et Suivi Objectif des Prairies), which is an operational application of the crop model (STICS) to estimate and map the real-time status of grass applied at the France scale (Ruget et al., 2006, 2009), the country is divided into approximately 200 small forage regions $\left(\sim 2500 \mathrm{~km}^{2}\right.$ each). In each region, representative classes of grassland were defined by combining the most frequent soil types, the common types of grassland (in terms of management, combinations of cutting-grazing and $\mathrm{N}$ fertilization) resulting in 25 typical pasture combinations. This system is used for example to quantify the impact of droughts on hay production (see http://agreste.agriculture.gouv.fr/ conjoncture/grandes-cultures-et-fourrages/prairies/). Up to now, ISOP does not simulate the Mediterranean regions which are specific because of irrigation. Recent approaches proposed to use remote sensing to inform some key inputs 
parameters of crop models (Di Bella et al., 2005; Duchemin et al., 2006; Jongschaap, 2006). Most of them uses the observed relationships between the normalized vegetation index (NDVI) computed from the reflectance measured in the optical range, and LAI (Baret and Guerif, 2006; Baret et al., 2007). Few works explored the possibility to obtain information on agricultural practices (Hadria et al., 2006; Launay and Guerif, 2005). The main reason of these few references was that, until now, there were no satellites which offered both high spatial and temporal resolutions well suitable to monitor agricultural practices. On one hand, sensors having a high spatial resolution such as ASTER (15 $\mathrm{m}$ in the visible range), Landsat $(30 \mathrm{~m}$ ) presented a low time revisit (16 days for time revisit on the same location). On the other hand, satellites with global coverage and high revisit (1 or 2 images/day) have typically a coarse spatial resolution (AVHRR, NOAA, $1 \mathrm{~km}$, and MODIS, $250 \mathrm{~m}-1 \mathrm{~km}$ ) or are also affected by the problem of varying viewing angle. Fortunately, with the continuous technological advances, new missions are available now such as FORMOSAT-2 launched in 2004 (http:// www.spotimage.fr/web/944-images-formosat-2.php) or are planned in the near future such as Venus (Dedieu et al., 2006) and Sentinel-2 (Martimort et al., 2007). The design of these new sensors allows now to provide both high spatial resolution $(\sim 10 \mathrm{~m})$ and frequent revisit time (few days) very appropriate both to the field scale and time step of agricultural practice variability.

A great experiment was conducted over the Crau region in 2006, including intensive ground measurements, along with FORMOSAT-2 image acquisition (Courault et al., 2008).

The study objective was to evaluate the feasibility of using FORMOSAT-2 data combined with a crop model to estimate production, evapotranspiration and drainage of irrigated grasslands at regional scale. The STICS crop model (Brisson et al., 1998) was chosen because:

- it simulates the soil (moisture and nitrogen daily evolution) and plant dynamic from biological and physical laws under the influence of the weather and agricultural practices which allows to test the crop response to environmental stresses, e.g. droughts, and to analyze various scenarios of practice modifications.

- STICS has been coupled with various remote sensing data in the past, for different applications (Di Bella et al., 2004; Guerif et al., 2007; Varella et al., 2010) and

- it has been developed and validated for grasslands by our team (Ruget et al., 2002, 2008, 2009).

\section{Studied site and data}

\subsection{Main features of the site and agricultural practices performed}

The Crau region is a flat area $\left(\sim 5 \mathrm{~m}\right.$ a.m.s.l., center: $43^{\circ} 38 \mathrm{~N}$, $5^{\circ} 00 \mathrm{E}$, see Fig. 1). The climate is typically Mediterranean, with irregular precipitations, long dry periods in spring and summer, and strong winds. Average cumulative rainfall is $600 \mathrm{~mm}$, but it has varied between $350 \mathrm{~mm}$ and $800 \mathrm{~mm}$ over the last 15 years. Mean air temperature is about $7-8^{\circ} \mathrm{C}$ in winter and about $24^{\circ} \mathrm{C}$ in summer. Wind is an essential meteorological component in Crau plain. It blows for about 110 to 160 days/year, and it often blows at more than $100 \mathrm{~km} / \mathrm{h}$. Such conditions increase intensively atmospheric demand in term of potential evapotranspiration $(\sim 1300 \mathrm{~mm} / \mathrm{year})$ and limit the possibilities of using aspersion irrigation technique (Mérot et al., 2008b).

The soil of the Crau region is shallow $(60-80 \mathrm{~cm})$ and very stony ( $20 \%$ of stone at the surface and $90 \%$ at about $80 \mathrm{~cm}$ deep) inducing a very low water holding capacity. It is also generally poor except at surface layers of irrigated fields which are rich in organic matter and mineral elements carried with time by irrigation water.

Permanent grasslands are the most irrigated crop in this plain (Mérot et al., 2008a) and cover about 13000 ha (23\% of the whole area), of which 12000 ha follow a governmental decree (http://www.foindecrau.com/cadre.htm). These crops are regularly irrigated from March to October from a dense channel network. Irrigation rounds are separated by 8 to 12 days (a round corresponds to the time between two irrigation events). Frequency is defined at the irrigation district level in order to ensure an equitable availability of water to each farm of the district. There are around 442 farms producing hay. More than $60 \%$ of these farms have an average area of 100-120 ha (Mérot et al., 2008a). Irrigation is managed by local association called ASA (Association Syndicale Autorisée). In addition, as the ground water table is superficial (at about $10 \mathrm{~m}$ from the surface), some farmers ( $~ 9 \%$ over the whole region) use pumping to irrigate some of their fields. This pumping is not regulated by the ASA and is only used one or two times per year for some fields far from the water point or very large and more sensitive to the drought in summer. Due to the flood irrigation technique and to the very stony soil type, about $60 \%$ of this water is lost by percolation and contributes significantly to the recharge of a superficial aquifer which is the main source of water for domestic use in this area. Water comes from the Durance river, supplied by the snowmelt from Alps. Future scenarios of global changes predict significant decrease in this water reserve, particularly during spring period.

The mowing is an important operation in grassland management. The dating of this practice is essential both for farmers and decision makers to better manage irrigation and manpower. Three hay harvests are produced throughout the 
year, with different floristic composition resulting in different economical values. In the decree to get the COP (certified origin product), the first cut must occur in May and in minimum 60 days after the pasture of the region. The delay between two successive cuts must be 40 to 70 days. The three cuts must be realized respectively before 31 May (Day Of Year: DOY 151), 25 July (DOY 206) and 30 September (DOY 272), except in case of special derogation. The decree specified also the drying periods and hay storage conditions.

\subsection{Ground measurements}

An experiment took place over the Crau region in 2006, including intensive ground measurements, in parallel to satellite data collection (Courault et al., 2008).

Classical meteorological measurements like rainfall, air temperature and humidity, wind speed, global and atmospheric radiations were recorded on a grassland field from March to October 2006. Values were averaged over a time step of $10 \mathrm{~min}$. The footprints of these last measurements ranged from 1000 to $3000 \mathrm{~m}^{2}$. For few intensive observation periods (IOP), surface fluxes were measured during several days. 1D anemometers (CA27T) were set up to compute the sensible heat flux $(H)$ from the eddy covariance method. Soil heat flux $(G)$ was measured using soil fluxmeters, put just below the surface. Pyranometers (CMC6) measured net radiation $(\mathrm{Rn})$ with an accuracy below $5 \mathrm{~W} / \mathrm{m}^{2}$. Finally, the latent heat flux (LE, equivalent to the actual evapotranspiration, AET) was obtained by the residual method of the energy balance:

$\mathrm{LE}=\mathrm{Rn}-H-G$

In the same time, the plant development was monitored by different observations and measurements. Crop heights $\left(h_{\mathrm{veg}}\right)$ were measured at different points of the field, distinguishing the floristic composition. LAI was estimated from hemispherical photographs. 40 to 60 photographs were taken along transects, according to the surface heterogeneity and to the field size, (the temporal sampling depended on the crop development). Then the CAN-EYE software (http://www. avignon.inra.fr/can_eye/page5.php, developed by Weiss and Baret at INRA Avignon) was used to process the image series and estimate different surface parameters such as fCover (vegetation fraction), FAPAR (fraction of absorbed photosynthetically active radiation) and the Effective LAI (which does not take into account vegetation clumping effect, and is comparable to remote sensing estimations) (Weiss et al., 2002, 2004). Sampling for the biomass estimation was also performed with the same time interval. Nitrogen analyses were made both on plant and in the soil for several dates between March and October.

In addition to these punctual accurate data, surveys were conducted on six farms (including more than 120 fields spatially distributed throughout the study area), to determine the
Table 1. Main statistics of mowing dates collected for 120 fields (Std: standard deviation, DOY: Day Of Year from the 1 January).

\begin{tabular}{llll}
\hline Observed date & First cut & Second cut & Third cut \\
\hline Min & 1 May (121) & 25 June (176) & 19 August (231) \\
Max & 28 May (148) & 20 July (201) & 4 September (247) \\
Average & 17 May (137) & 7 July (188) & 26 August (238) \\
Std (days) & 6.5 & 5.5 & 4.5 \\
\hline
\end{tabular}

agricultural practices and to understand how farmers manage their crop in real conditions. Thus mowing and irrigation dates were collected,with information on yield and nitrogen quantities brought by the farmer to each field.

Table 1 shows the variability observed for the mowing date of 120 investigated fields. It appears that the period for the first mowing took 27 days, which involved consequently a wide difference for the development between the fields.

\subsection{FORMOSAT-2 data: description, processing and derived products}

FORMOSAT-2 is a Taiwanese satellite (http: //www.spotimage.fr/web/944-images-formosat-2.php)

operational since May 2004 on a sun-synchronous orbit, with onboard Remote Sensing Instrument (RSI). RSI provides high spatial resolution images $(8 \mathrm{~m}$ in the multispectral mode for nadir viewing) in four narrow spectral bands ranging from $0.45 \mu \mathrm{m}$ to $0.90 \mu \mathrm{m}$ (blue (B), green $(\mathrm{G})$, red (R) and near-infrared (NIR). Unlike other systems operating at high spatial resolution and thanks to its orbital cycle of one day, FORMOSAT-2/RSI observes a particular area potentially every day with a constant viewing angle. However, only about the half of the Earth is observed by this satellite (Chern et al., 2006). During the 2006 experiment, thirty five FORMOSAT-2 images were acquired every 3 to 4 days during 8 months at 10:30 TU from March to October 2006, and with a constant viewing angle of $41^{\circ}$ over the Crau region. These images were first geolocated, registered and calibrated at CNES (Centre National d'Etudes Spatiales, France, according to the method described in Baillarin et al., 2004). Then the clouds and their shadows were discarded, and the images were corrected from atmospheric effects using the multi-temporal aerosol detection method developed by Hagolle et al. (2008).

Due to these specific characteristics, FORMOSAT-2 images offer strong opportunities for crop monitoring with a spatial resolution of $8 \mathrm{~m}$ very suitable to identify each field and surface modifications as displayed on Fig. 2.

All FORMOSAT-2 images were processed to obtain NDVI and LAI maps. Various other vegetation indices were proposed in the literature (Huete et al., 2002), but the strength of NDVI is in its ratioing concept, which reduces many forms of multiplicative noise (illumination differences, cloud 


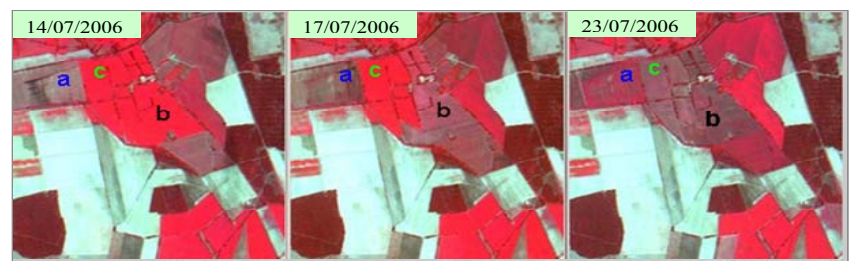

Fig. 2. Combination between 3 spectral bands $(G, R, \mathrm{NIR})$ of FORMOSAT- 2 images for 3 consecutive dates in July acquired over a small area $(2 \times 2 \mathrm{~km})$ of the Crau region, showing the mowing of grasslands (in red): the "c" field was the last mowed.

shadows, atmospheric attenuation, certain topographic variations) present in multiple bands. Bsaibes et al. (2009) compared different models proposed in literature and found that a simple algorithm based on the exponential law using NDVI gave satisfactory results compared to ground measurements for several crops in the Crau region. Thus the following formula was used:

$\mathrm{LAI}=-\left(\frac{1}{K_{\mathrm{LAI}}}\right) \cdot \ln \left(\frac{\mathrm{NDVI}-\mathrm{NDVI}_{\infty}}{\mathrm{NDVI}_{\mathrm{s}}-\mathrm{NDVI}_{\infty}}\right)$

With $K_{\mathrm{LAI}}=0.71, \mathrm{NDVI}_{\infty}=0.89, \mathrm{NDVI}_{\mathrm{s}}=0.1$. FORMOSAT data were acquired with the same viewing angle during all the period. Data measured on five fields at different development stages were used for validation (representing 97 samples). Leaf Area Index (LAI) was derived from hemispherical images that provided Effective LAI. For LAI estimation, ground based measurements and FORMOSAT-2 pixels were collected or selected in order to consider representative values at the field scale. Ground samples were collected within each field according to a cross-pattern protocol, and next averaged. For each field, FORMOSAT-2 overlaying pixels were selected by excluding borders, and the corresponding waveband reflectances were averaged to compute NDVI. A "leave-one-out" cross validation method (described in Bsaibes et al., 2009) was implemented to estimate the accuracy. Various standards metrics were computed among them RMSEa, (absolute root mean square error). This last term was in the order of magnitude of $0.66 \mathrm{~m}^{2} / \mathrm{m}^{2}$ which was quite good for LAI estimations (Bsaibes et al., 2009). Other approaches were proposed to estimate LAI, based for example on the use of radiative transfer models, or neutral network (Weiss et al., 2002, Bsaibes et al., 2009). Radiative transfer model inversion is potentially a very powerful approach. But although using deterministic approaches has more portability than empirical approaches, it required first inversion strategies that face the ill-posed problem and related equifinality troubles.

A land-use classification was then made in order to separate the grasslands from the other land-use classes. The land cover classification was based on a maximum likelihood supervised classification. The latter used the 4 spectral bands of 5 images distributed along the experimental period. Ref- erence areas from known field are defined for classification. Then all fields were manually delineated and digitized. As the spatial resolution of FORMOSAT was high $(8 \mathrm{~m})$, each grassland field was identified correctly. The digitization result was then superimposed to the NDVI maps to extract for each date the NDVI profile of each grassland field. Figure 3 presents the temporal evolution of NDVI of all the fields of two farms investigated. The periodicity due to the three mowing events appeared clearly. A wide variability of mowing dates was observed within a given farm. This gave also an idea about the duration needed to cut the grasslands of all fields of a given farm. The first cut generally needed more time (see the three numbers between brackets, values varying between 16 and 20 days) than the second one. This was explained by the fact that the total production decreased from the first to the third cut (average produced hay for a farm was $4.3 \mathrm{t} / \mathrm{ha}, 2.8 \mathrm{t} / \mathrm{ha}$ and $1.8 \mathrm{t} / \mathrm{ha}$ for the first, the second and the third cut, respectively). For these reasons, managing the two first cuts took more time than the third one. All NDVI curves reached a minimum value ranging between 0.36 and 0.53 after the cut and before starting to increase. The dates corresponding to these minimum varied from one field to another and also from one farm to another. Irrigation frequency varied also considerably from one farm to another one (see the number after the word "irrig" in the top of each figure) from 8 to 12 days for the whole studied area.

\section{Methods}

In this section, only the main variables necessary to provide to the crop model are described (some of them were derived directly from remote sensing data, and the other were estimated indirectly from primary variables). Then the original approach proposed to combine STICS with these data is presented to estimate production and water balance at both field and regional scales.

\subsection{Estimation of the mowing dates from FORMOSAT- 2 images}

From these previous observations, a simplified approach was proposed to estimate the mowing dates from FORMOSAT-2 images. It consisted in, first detecting the date of NDVI minimum followed by a NDVI increase for the next four image acquisitions. Then 6 days are removed from the date corresponding to this minimum because this time interval corresponded to the period needed to dry and to collect hay. This method was applied at regional scale over more than 1500 grassland fields. The validation gave satisfactory results with high correlations between simulations and observations $\left(r^{2}>0.9\right.$ with rmse respectively of 2.5 days for the first cut, 1.3 and 4 days for the 2 nd and 3rd cuts). It should be noted here that the relatively lower value for the third cut was mainly due to the lower number of images for this last 

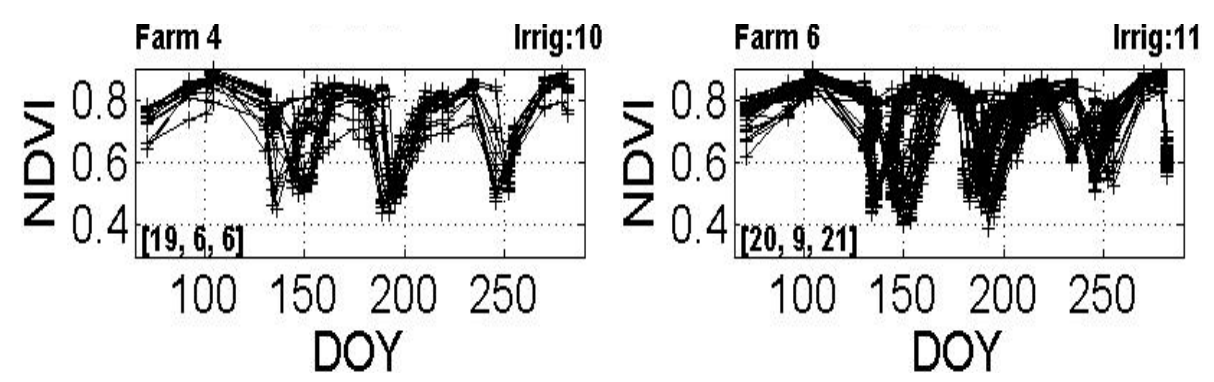

Fig. 3. FORMOSAT-2 NDVI temporal evolution of fields surveyed beside two farmers. Each figure corresponds to one farm and each curve represents a field within this farm. The three numbers between brackets indicate the period needed for the 1st, 2nd and 3rd cuts, respectively. The number in the top after the word "irrig" corresponds to the irrigation round.

Table 2. Mowing date estimated from FORMOSAT images.

\begin{tabular}{llll}
\hline Estimated date & First cut & Second cut & Third cut \\
\hline Min & 4 May (124) & 24 June (175) & 18 August (230) \\
Max & 30 May (150) & 21 July (202) & 4 September (247) \\
Average & 16 May (136) & 6 July (187) & 30 August (242) \\
Std (days) & 7.5 & 5.9 & 17 \\
\hline
\end{tabular}

period because of the higher occurrence of clouds over the studied region. Table 2 presents the results obtained for the fields investigated. Compared to Table 1 , the results were quite satisfactory. Figure 4 shows the maps of the first mowing date (a) and the LAI obtained on DOY 151 (b) over a small area, when all the fields were cut.

These two maps show logically strong correlations. The fields with the lowest LAI values were the last mowed. On the contrary, the first mowed fields which had more time to develop biomass presented higher LAI values. The time interval for mowing all the fields (20 days for the first cut) was enough to lead to a wide variability of LAI between fields, up to $5 \mathrm{~m}^{2} / \mathrm{m}^{2}$ just after the first cut. This discrepancy between fields increased up to $6-7 \mathrm{~m}^{2} / \mathrm{m}^{2}$ at the end of October.

\subsection{Estimation of irrigation dates}

It is often difficult to get an exhaustive information on irrigation over a region, particularly when it's flooding: (1) because the water quantities brought to each field are not known with accuracy, (farmers bring generally more water than the real need of plants and have no ideas about the exact quantity), (2) in addition, in the Crau region, there is a complex water distribution managed by different associations (called ASA), linked to each main channel. Each ASA has its own peculiarities for the irrigation frequency for example varying from 8 to 12 days. Thus, facing a lot of unknown variables related to irrigation, an indirect approach was proposed to derive some key parameters such as the irrigation dates from the knowledge of the mowing dates. Indeed, we observed that generally the first cut fields were the first irrigated just
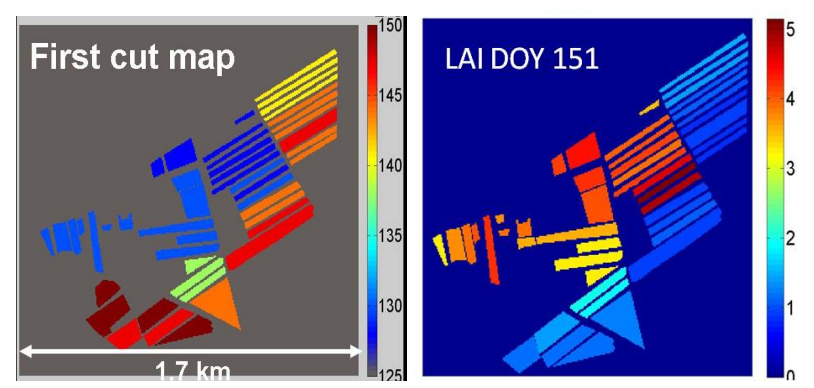

Fig. 4. The first mowing date (in DOY) mapped from the simplified algorithm described in Sect. 3.2, LAI $\left(\mathrm{m}^{2} / \mathrm{m}^{2}\right)$ map obtained from the Eq. (2), on DOY 151 (31 May 2006).

after the harvest. A linear relationship was found between mowing and irrigation dates extracted from the field surveys (Fig. 5). Then, as the starting date and irrigation round were known for each ASA, the different irrigation dates could be estimated for each field. Then, water supplied at each event was set up at $100 \mathrm{~mm} /$ day (this value was chosen from measurements performed on an experimental field by (Mérot et al., 2008b). This water quantity was set as a constant value in time for each field.

\subsection{Brief review of the STICS crop model}

STICS ("Simulateur mulTIdisciplinaire pour les Cultures Standards") has been developed since 1996 at INRA of Avignon in France (www/avignon.inra.fr/agroclim_stics_eng/ modele_stics). It is a crop model running at a daily time step with inputs describing climate, soil, plant and crop system. Among the main outputs, there are yield in term of quantity and quality, and environment terms linked to drainage and nitrate leaching (Brisson et al., 2003). The simulated object is the crop situation for which a physical medium and a crop management schedule can be determined. The main simulated processes are crop growth and development as well as the water and nitrogen balances. The model is based on three functional types: 


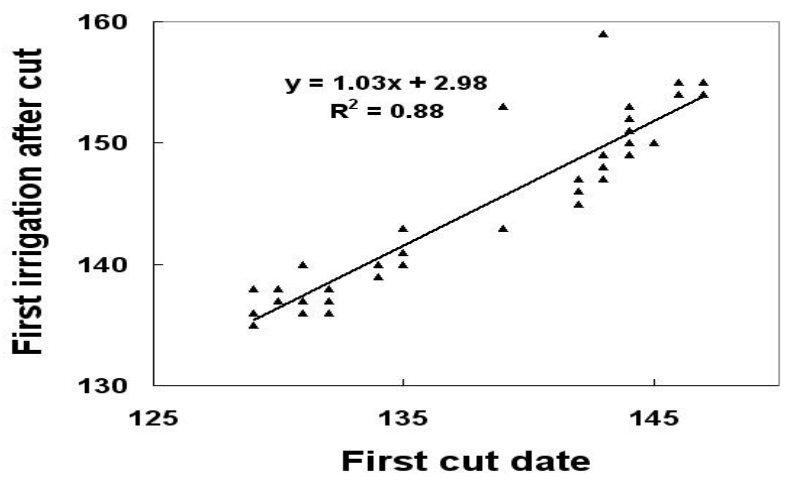

Fig. 5. Relationship obtained between the 1st mowing date and the irrigation date just after the mowing, for the different grasslands surveyed over the Crau region.

- a physiological period defines the growing stages (development module), using a thermal (degree-day) or photo-thermal index according to the species;

- within each of the vegetation phases, defined by the calendar, the crop growth functions depend on uncontrollable climatic variables (temperature and radiation). There are shoot growth functions without action of roots (leaf area setting, light interception, conversion of intercepted light, partition to grain modules). Only the shoot is considered;

- the third type of function simulates the effects of water and nitrogen stresses: it requires root growth in order to have access to the water and nitrogen resources (rooting, water balance, mineralisation and nitrogen balance modules).

STICS has a modular design that allows the addition of new developments (e.g. ammoniac volatilisation, symbiotic fixation and organic residues). Each module deals with specific mechanisms. A first set of three modules concerns the ecophysiology of shoots, (development, vegetative growth, yield components), and a second set of four modules deals with the ways in which the soil functions interact with the underground parts of plants (root growth, water balance, nitrogen balance, soil transfers). At the interface there is a module dealing with managing interactions between cultivation techniques and the soil-crop system, whether in the form of water supply, fertiliser supply or the microclimate.

The phenological development of the crop is mainly controlled by canopy temperature, while the carbon balance drives biomass accumulation. STICS can either simulate LAI evolution varying according to water and nitrogen stress, either use daily values of LAI provided as forcing inputs. The quantities/doses of water can be also imposed as an input variable or calculated by the model.

Concerning the grassland, the cutting of grass can be achieved using one of three methods:
(1) automatic calculation: as soon as the crop reaches the stage defined by a agricultural parameter fixed in the model, it is cut at the cutting height corresponding to the height defined as the maximum, and then transformed into biomass using a conversion coefficient,

(2) imposed date: in this case, a table of different cutting dates is used as input model, associated with the following elements: residual LAI and dry matter, fertilisation,

(3) cutting dates are defined by cumulative development units, expressed in cumulative temperatures.

The soil is considered as a succession of horizontal layers and each layer is characterized by its water, mineral and organic nitrogen content. STICS simulates the evolution of these last variables. On a daily time scale, root uptake can be considered to be equal to leaf transpiration. Root uptake calculated overall, is then distributed between the soil layers. Relative transpiration is defined as the ratio between actual transpiration (AET) and maximal transpiration (EP) and is a bilinear function of the available water content in the root zone. The minimal value for the soil water content corresponds to the wilting point, whereas the maximal value corresponds to the difference between the water content at field capacity and that at the wilting point. The water content threshold separating the maximal transpiration stage and the reduced transpiration stage depends on root density, the stomatal functioning of the plant, and climatic requirements. Two approaches are proposed to compute evapotranspiration: a crop coefficient approach and a resistive approach according to the Shuttleworth and Wallace's model (Brisson et al., 1998). Catalogues of various parameters are defined for several crops, and agricultural practices (Launay et al., 2009). Ruget et al. (2006) conducted a sensitivity analysis to choose the main parameters of the model. In our case, it appeared that the most important parameters were those related to the agricultural practices: mowing and irrigation dates. As these parameters varied significantly at regional scale, the model was used with the imposed dates derived from FORMOSAT-2 images (described in Sects. 3.1 and 2), and with LAI as input data (Fig. 5). For this last condition, linear interpolation had to be made between FORMOSAT- 2 dates to get daily values of LAI for each plot. Residual LAI values were then determined for each field after cut, and residual dry matter deduced from these last values.

In a first stage, the model results were checked at field scale where local measurements were available. Then the model is applied at farm scale over 47 fields (130 ha). In this last case, a homogeneous soil type was considered for all fields with the same characteristics as summarized in Table 3. In the same way, since the fertilisation didn't present a great variability at this spatial scale, only one nitrogen fertilisation of $60 \mathrm{~kg} / \mathrm{ha}$ was supplied on 20 May for all the fields. However, it should be noted that the grassland age being very different between some fields (more than 80 years apart), this 
Table 3. Summary of the main inputs necessary for STICS (Tmin, max: minimum and maximum air temperature, HR: air moisture, Rg: global radiation, $U$ : windspeed, $N$ : nitrogen content, ASA: Association for water management).

\begin{tabular}{lll}
\hline Input parameters & Data & Origin/value \\
\hline Climatic data (daily) & Rain, Tmin, Tmax, $U, \mathrm{HR}, \mathrm{Rg}$ & weather station on grassland \\
Plant (monospecific) & LAI (daily) & FORMOSAT images \\
& Residual LAI after cut & FORMOSAT images \\
& Residual dry matter after cut & Deduced from residual LAI \\
Agricultural practices & Mowing date & FORMOSAT images \\
& Irrigation date & FORMOSAT images \\
& frequency, dose (water) & ASA, 100 mm/event \\
& Nitrogen fertilisation, date, dose & Surveys: 20 May, 60 kg/ha \\
& Layer number $(2)$, & Soil map \& soil analysis \\
& Depth, Texture, $\%$ stone & $80 \mathrm{~cm}, 20 \%$ silt, $60 \% \mathrm{stone}$ \\
& Initial Soil moisture & Measurements: $10 \%$ 20\% \\
& Initial $\mathrm{NO}_{3}, \mathrm{NH}_{4}$, Norg contents & Analysis $80 \mathrm{~kg} / \mathrm{ha}+\mathrm{knowledge} \mathrm{f}$ \\
& & (grassland age) \\
\hline
\end{tabular}

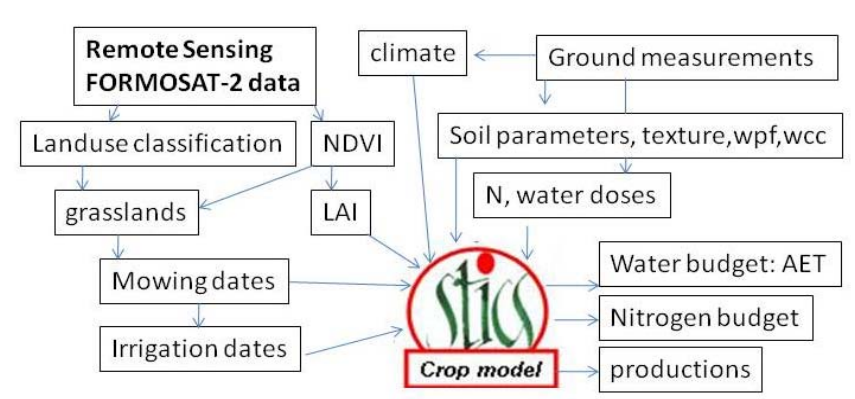

Fig. 6. Approach proposed to couple remote sensing data acquired at fine resolution and STICS crop model for assessing yields and water budgets at regional scale.

fact has led to a spatial variability of organic nitrogen in the soil. Thus the initial parameters linked to nitrogen in the soil were defined according to the mean values measured on the reference field and the expert knowledge, taking into account standard values found in the literature (Ruget et al., 2009). Figure 6 summarizes the approach proposed to combine STICS crop model and high spatial and temporal resolutions FORMOSAT- 2 data to assess yield and water budgets at regional scale. In order to evaluate the contribution of remote sensing in the crop model, comparisons between simulations with and without forcing from FORMOSAT data were done. The results of this comparison will be presented in the discussion section.

\section{Results}

\subsection{Field scale}

Figure 7a presents the LAI values measured in the reference field from hemispherical photographs, then linearly interpolated at daily time step, and compared with the LAI derived from FORMOSAT-2 images computed from Eq. (2) (Sect. 2.3).

Three cycles of grassland growth appeared clearly, separated by three cut events: the first cut was on DOY 131 (11 May), the 2nd cut on DOY: 189 (7 July) and the last one on DOY: 234 (22 August). A good agreement is observed between LAI estimated from FORMOSAT-2 with ground measurements, except for the second cycle, where the spatial variability of the measurements was the highest. Just before mowing, very high values of LAI were estimated corresponding to high NDVI values. Many authors have shown that when LAI was higher than 4 , NDVI tend to saturate (Combal et al., 2003). Thus the accuracy for high LAI values can be arguable. That can explain the difference observed between simulations and measurements for these periods.

The comparison between aerial biomass estimated by STICS and observed biomass (Fig. 7b) gave quite good results with rmse of $0.25 \mathrm{t} / \mathrm{ha}$ for the total amount of biomass. The model was able to simulate correctly the biomass dynamics with the seasonal variability: the decrease in production classically observed from the first to the third cut. This was mainly explained by the variation in floristic composition which varied according to the season.

Measurements of nitrogen content in the soil were also evaluated in comparing the nitrogen stress index simulated by STICS (Fig. 7c). The model was also able to simulate this variable correctly. Two periods appeared clearly: The first period from the 1srt January to the end of February 
Table 4. Main terms of the water budget and biomass obtained for the reference field from 1 January 2006 to 30 September 2006 with STICS.

\begin{tabular}{lllll}
\hline Rain & Irrigation & AET & Drainage & Biomass \\
\hline $505 \mathrm{~mm}$ & $2300 \mathrm{~mm}$ & $936 \mathrm{~mm}$ & $1680 \mathrm{~mm}$ & $13.8 \mathrm{t} / \mathrm{ha}$ \\
\hline
\end{tabular}

(DOY 59), characterized by a nitrogen stress index superior to 0.6 , which corresponded to the stages of crop development requiring generally fewer nitrogen resources. The second period from the beginning of March (DOY 60) to the end of October was characterized by stress varying around 0.5 . It was the irrigation period. The peak observed around DOY 140 corresponded to a nitrogen supply $(60 \mathrm{~kg} / \mathrm{ha})$. Even after this nitrogen supply, the nitrogen index still remained low. Indeed, a great quantity of nitrogen was leached by drainage, as the soil was not deep enough to keep reserves for a long time, as well as due to the flooding which led to supply more water than needed, and huge water quantities were lost by drainage and went directly to the ground table.

Few evapotranspiration values (AET) were available during the experiment and compared to those simulated by STICS (Fig. 7d). rmse was in the order of $1.4 \mathrm{~mm} /$ day, value currently found in literature for such comparisons. A high variability was observed from one day to another, mainly due to the agricultural practices. Indeed, AET passed from $7 \mathrm{~mm} /$ day just before mowing to $0.5 \mathrm{~mm} /$ day after cut. Irrigation events led also to great variations in AET, particularly in summer.

Finally, Table 4 gives a summary of the main terms of the water budget and the total production simulated for this reference grassland field. The drainage term which corresponds to the water excess computed by STICS, represented almost $60 \%$ of the total water amount supplied by irrigation plus rainfall. This result was consistent with values reported in different papers by (Mérot et al., 2008a, b; Mailhol and Mérot, 2008).

\subsection{Farm scale}

Considering the previous results as globally satisfactory, STICS was applied at a larger scale, a farm including 47 fields $\left(\sim 4 \mathrm{~km}^{2}\right)$. On this area, only the main agricultural practices (irrigation and mowing dates) and yields were known. Daily LAI maps were provided as inputs to the crop model, as well as maps of irrigation and mowing dates derived from FORMOSAT-2 image processing described in Sect. 3, and values of residual LAI and dry matter obtained just after the cuts.

Figure 8 displays the daily biomass maps simulated the 4 and 9 June 2006 with the corresponding evapotranspiration maps. These maps allowed monitoring crop develop-

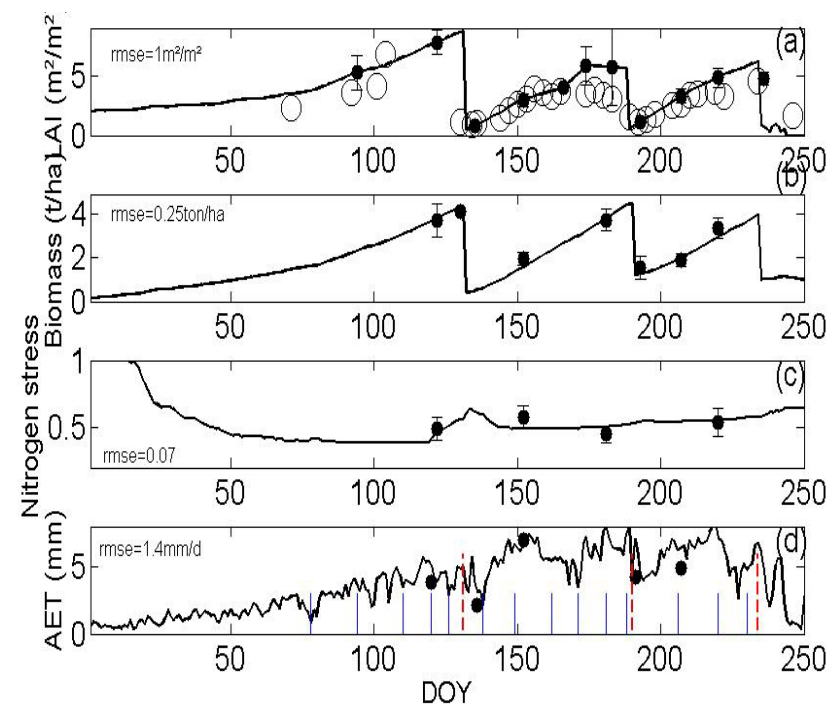

Fig. 7. Comparisons between STICS simulations and measurements performed on the reference field for the period: 1 January-30 September 2006 for: from top to bottom (a) LAI $\left(\mathrm{m}^{2} / \mathrm{m}^{2}\right)$ FORMOSAT and measurements (b) Biomass (t/ha), (c) nitrogen stress index (d) AET ( $\mathrm{mm} /$ day), computed in STICS according to the Shuttleworth and Wallace method. The red lines represent the cut dates and the blue lines, the irrigation dates.

ment and water consumption. A great variability was observed due to the agricultural practices. Some grasslands (not yet mowed on DOY 155, or the first cut (DOY 160) were well developed (crop height was around $70 \mathrm{~cm}$, LAI around $6 \mathrm{~m}^{2} / \mathrm{m}^{2}$ ), therefore biomass were important with high AET values. Evapotranspiration could reach values up to $7.5 \mathrm{~mm} /$ day when fields were irrigated, and decreased down to $0.5 \mathrm{~mm} /$ day for fields not yet flooded. At the end of the season, total amounts could be computed for the biomass and water consumption. Satisfactory results were obtained for simulated yield at the end of each cycle, compared to the values given by the farmer (Fig. 9). For the first harvest, one field (no. 18 on Fig. 9) showed a very high value for yield quite different from the others. This field was mowed first, additionally, it was close to a channel, and received a nitrogen supply during 2006. For the harvests that followed, the results were globally satisfactory with a most important scattering for the third cycle. Some fields (50-51-52) having the lowest yields corresponded to the more recent grasslands (sown after 2000), while the oldest fields (sown before 1950) produced generally more biomass. Significant differences were also observed for the LAI between these fields. An explanation could be that the soil under the older fields is slightly deeper and more silted than those of the recent fields, because of the sediments supplied by irrigation during numerous years.

It appeared that even at a small spatial scale, there were a great variability both in yields, evapotranspiration and drainage terms. This variability was strongly linked with 


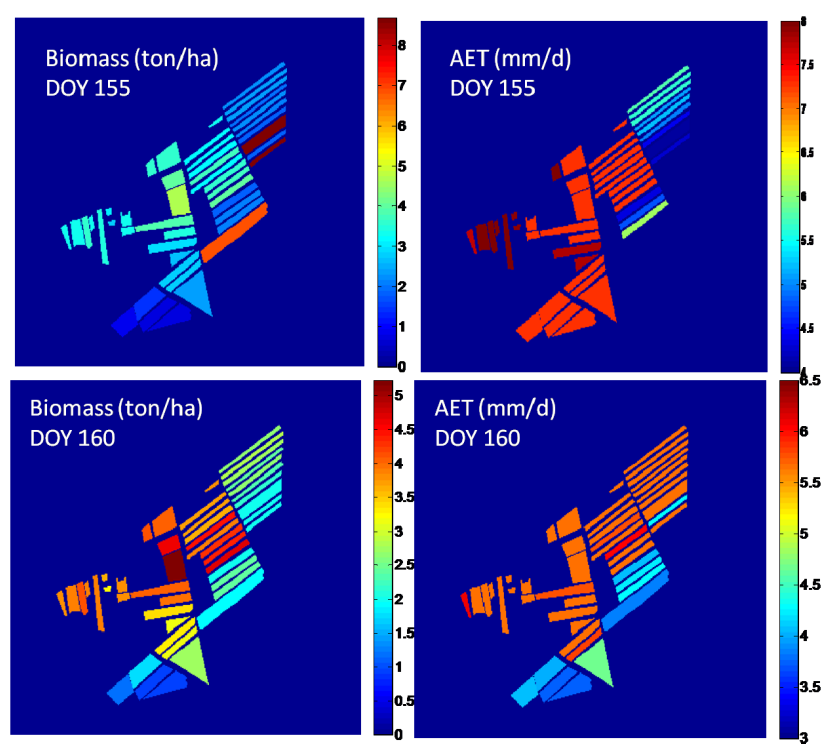

Fig. 8. The biomass and evapotranspiration simulated by STICS on 4 and 9 June 2006 (DOY 155 160).

the irrigation order and consequently with the order of mowing the fields. The last mowed fields could receive one or two irrigation supplementary for the same period which explained substantial differences in the order of magnitude of $105 \mathrm{~mm}$ for cumulated evapotranspiration from one plot to another. This discrepancy appeared also logically in the drainage term, representing the difference between water supplied by irrigation and rainfall, and the amount of water lost through evapotranspiration processes. The dynamics of the ground table level was thus strongly dependant on the irrigation performed from March to October. Observations recorded from some piezometers set up in the studied area have shown that the ground-table level varied at around $4 \mathrm{~m} /$ year during this period (Anne Laure Cognard, personal communication, 2009).

\section{Summary-discussion}

The general objective of this work was to develop method combining remote sensing data acquired at high spatiotemporal resolutions and a crop model for monitoring irrigated grasslands in Mediterranean regions. Our study was focussed on assessing the potentials of FORMOSAT-2 images linked to the STICS crop model to estimate water balance and production of irrigated grasslands in the Crau region in the South Eastern France. STICS was first validated from ground measurements performed over a reference field, then applied at farm scale to 47 fields. Satisfactory results were obtained for yield estimations. A great spatial variability was observed mainly due to the variability of the agricultural practices performed at field scale (irrigation and mowing). It appeared that the high temporal (time revisit of around 3 days in our case) and spatial resolutions (8 m) of FORMOSAT-2 data were well suitable for the identification of these main agricultural practices. Surface parameters such as LAI could be easily estimated using a simple algorithm. The mowing and irrigation dates were mapped from simplified approaches based on the analysis of NDVI profiles. These maps reproduced correctly the spatial variability observed at regional scale.

In order to quantify the contribution of knowing this information provided by remote sensing, comparisons between simulations for the different cases presented in Table 5 were analysed. The results were compared with the observed total biomass. In the first two cases, simulations were performed without remote sensing information. LAI was computed by STICS, from cumulated temperatures varying according to water and nitrogen stresses. Irrigation and mowing dates were also computed by the model as explained in Sect. 3.3. Irrigation occurred when the water stress index was below 0.8 , which meant that the grasslands were globally well supplied with water. Two irrigation water quantities were chosen: case 1: $20 \mathrm{~mm}$, case 2: $40 \mathrm{~mm}$ brought at each event. For these two situations, there was no variability, all the fields had the same behaviour. The total biomass simulated was then compared to the observation average of all fields surveyed. The following cases (3-4-5-6) introduced the spatial variability at different levels, only in fixing the mowing dates (3), or irrigation dates, the LAI or the combination of these variables. The best results were obtained for the biomass estimation when all the variables (LAI, mowing and irrigation dates) were forced into the model from remote sensing data. It appeared also that the knowledge of the variability of agricultural practices was most important than the knowledge of LAI only, which was not surprising since the agricultural practices were crucial for the vegetation development. It should be noticed also that for three times less of water, the simulations (cases 2-6) gave the same production level. Irrigation by flooding consumes generally more water than the real need. It is the traditional method used for century, with a strict water round defined at the district level. If severe droughts increase in the next years, the frequency and duration of irrigations has to be revised. Tools such those proposed here would allow to analyze different scenarios and propose suitable strategies to maintain reasonable production in saving water. These proposals must be also discussed with economists in order to take into account all the other water uses in the region.

Forcing STICS with remote sensing data acquired at high spatio-temporal resolution allowed to estimate significant differences for both the biomass production (from 9 to $14 \mathrm{t} / \mathrm{ha}$ ), and the main water budget terms at farm scale. Simple algorithms for mapping LAI and agricultural practices easy to implement to other dataset or regions for operational applications were proposed. However, several points still remain to improve which are listed below. 

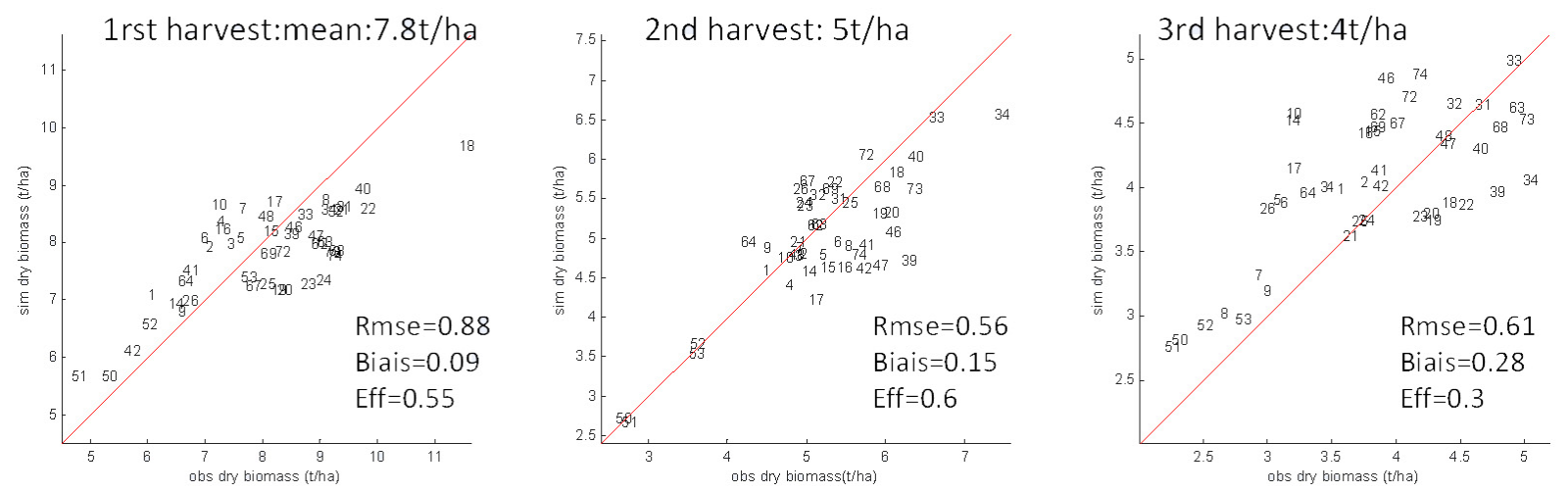

Fig. 9. Comparison between biomass observed and simulated by STICS for the 47 fields of the studied farm.

Table 5. Comparison between STICS simulations where main inputs (LAI, cut and irrigation dates) varied for the period 1 January-31 October 2006 (forced meant computed from remote sensing data, simulated: computed by the model; cases 1 and 2, only one simulation was performed and compared to the average of yields observed over the 47 fields surveyed + rmse, for the other cases, rmse: relative standard error and bias were computed).

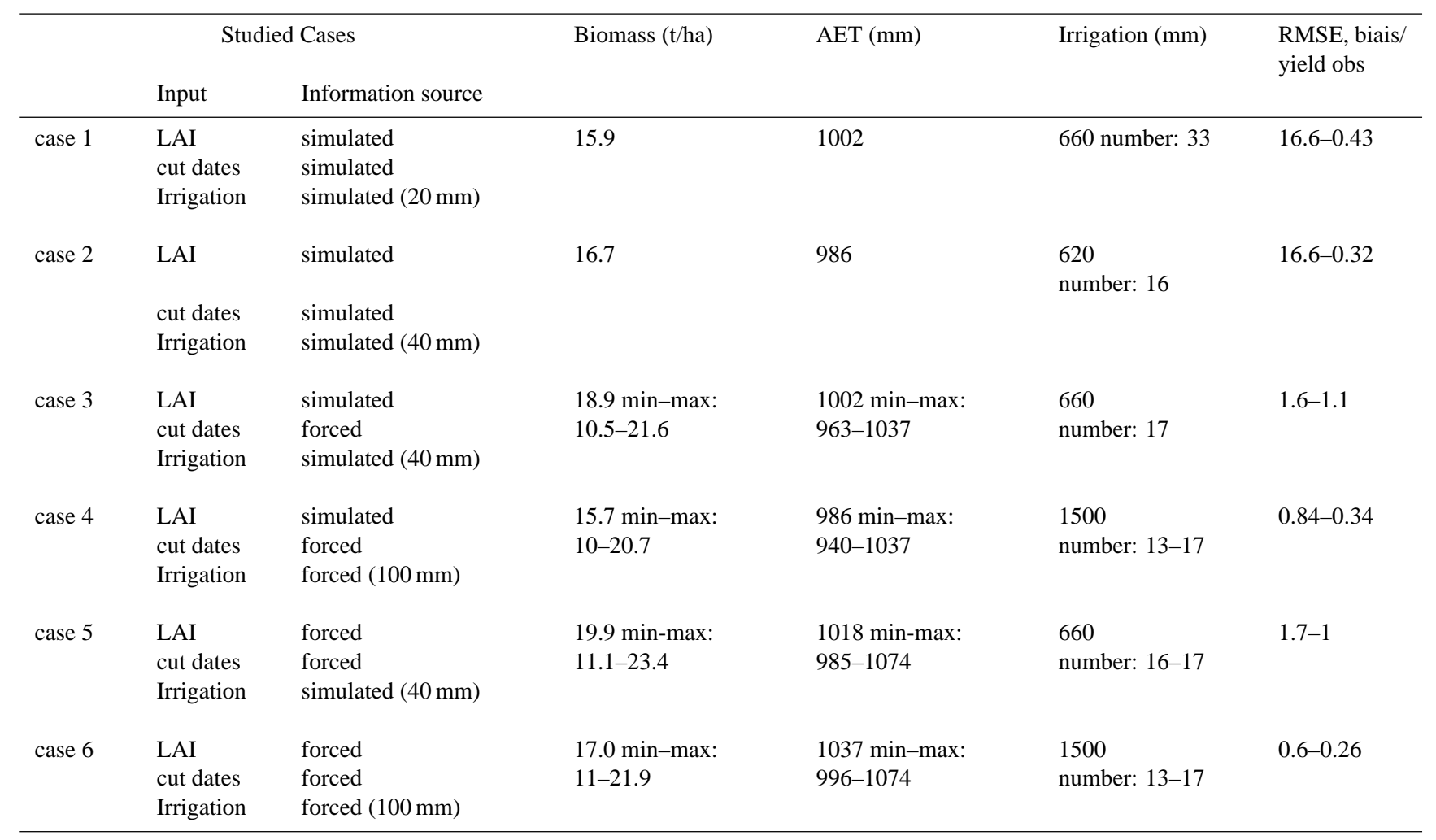

The validation at this regional scale is often a problem, because generally there are no observations or measurements everywhere of numerous variables. In our case, only yields observed for 120 fields were collected. For the next years, it should be noted that new micrometeorological stations will be set up with continuous measurements of evapotranspiration, associated with observations of the ground table levels recorded at regular time step on three additional grasslands in the Crau region. These measurements should allow to check our future simulations, but these validations will be always very punctual. An alternative would be to compare evapotranspiration maps simulated by STICS with maps obtained from another models simulating soil vegetation atmosphere transfer (SVAT models, for example, SEBAL, see Courault et 
al., 2008). This approach would have the advantage to cover all the study area but concerns only few dates where thermal data are available (if SEBAL is used). This track is currently being studied in our laboratory.

Another point to improve is with respect to the irrigation. In flooding irrigation method, generally, a great water quantity is lost by drainage (up to 60\%). In this study, constant water supply $(100 \mathrm{~mm} /$ irrigation event $)$ was prescribed for each field. It was a first simplified approach necessary to improve because this quantity can vary according to different factors among them: soil permeability, regional water managers... This water amount could be better fit using assimilation procedures into STICS model (Olioso et al., 2005). That supposes to find observations strongly linked with the soil water content. In addition, these observations must be acquired with a fine time step for following irrigation practices ( $<10$ days). Numerous studies have discussed about the potentialities of thermal or microwave data for assessing soil moisture variability (Jacob et al., 2008; Wigneron et al., 1999). But currently, there are no satellites which provide similar temporal and spatial resolution such as FORMOSAT-2 in this spectral range. MODIS (EOS) or AVHRR (from NOAA meteorological satellites) deliver thermal data on a daily basis but with a coarse spatial resolution of $1 \mathrm{~km}$. A higher resolution was achieved by Landsat (TM: $120 \mathrm{~m}$, ETM: $60 \mathrm{~m}$ ), and ASTER $(90 \mathrm{~m}$ ) but the time revisit is low (16 days), and do not allow to detect grassland irrigation occurring with on average every 10 days in our study region. There is currently a strong demand from the scientific community for having thermal sensors with finer resolution, such as the former European Space Agency candidate Earth Explorer mission, SPECTRA mission (Jacob et al., 2008), or future MISTIGRI mission currently in study by CNES (Garcia Moreno et al., 2009) or HyspIRI (see http://hyspiri.jpl.nasa.gov/). It should be noted also the future high-temporal SAR data eg Sentinel-1, (see http://space.skyrocket.de/index_frame.htm?http://space. skyrocket.de/doc_sdat/sentinel-1.htm/) which should provide also data at high resolution useful for the surface moisture monitoring.

\section{Conclusions}

This study demonstrated that remote sensing data acquired at high spatio-temporal resolution could give useful information on the variability of agricultural practices at regional scale. The introduction of these data into a crop model improved significantly results on the biomass estimation, and made possible a daily crop and water monitoring. The method proposed here appears thus as an useful tool for water managers or farmers and can be easily applied to other regions or to different crops, if similar data such as FORMOSAT-2 data are available. As mentioned in the introduction, only a part of the world is covered by FORMOSAT-2, but with plethora of satellites around the world, and the future sensors like Sentinel or Venus (Dedieu et al., 2006) with characteristics similar to FORMOSAT-2, it would be possible to get data at fine resolution with a high revisit time for the next years in numerous regions. Sentinel 2 would cover all the earth and will be used in to Global Monitoring for Environment and Security program (GMES), (http://esamultimedia.esa.int/docs/GMES/ GMES_Sentinel2_MRD_issue_2.0_update.pdf). Crop models forced with such remote sensing data have thus an added value as the agricultural practices performed at landscape scale can be accurately detected and mapped. This should help us in the future, to quantify the impacts of practice modifications due to global changes, both on crop production and environment.

Acknowledgements. This study was part of projects financed by the MIP-PACA regions in France and by the CNES (DAR 2006 TOSCA). The FORMOSAT-2 images used in this study are (C) NSPO (2006) and distributed by Spot Image S. A. all rights reserved. Authors thank the different institutions and farmers for surveys and measurements performed on their fields.

Edited by: D. Fernndez Prieto

\section{References}

Baillarin, S., Gleyzes, J. P., Latry, C., Bouillon, A., Breton, E., Cunin, L., Vesco, C., and Delvit, J. M: Validation of an automatic image orthorectification processing. IGARSS's Proceedings, 2024 September 2004, 2, 1398-1401, ISBN1390-7803-8742-1392, 2004.

Baret, F. and Guerif, M.: Remote detection and quantification of plant stress: opportunities remote sensing observations, Comparative Biochemistry and Physiology a-Molecular \& Integrative Physiology, 143, S148-S148, 2006.

Baret, F., Hagolle, O., Geiger, B., Bicheron, P., Miras, B., Huc, M., Berthelot, B., Nino, F., Weiss, M., Samain, O., Roujean, J. L., and Leroy, M.: LAI, fAPAR and fCover CYCLOPES global products derived from VEGETATION - Part 1: Principles of the algorithm, Remote Sens. Environ., 110, 275-286, doi:10.1016/j.rse.2007.02.018, 2007.

Barrett, P. D., Laidlaw, A. S., and Mayne, C. S.: GrazeGro: a European herbage growth model to predict pasture production in perennial ryegrass swards for decision support, Eur. J. Agronomy, 23, 37-56, 2005.

Bergez, J. E., Deumier, J. M., Lacroix, B., Leroy, P., and Wallach, D.: Improving irrigation schedules by using a biophysical and a decisional model, Eur. J. Agronomy, 16, 123-135, 2002.

Brisson, N., Mary, B., Ripoche, D., Jeuffroy, M. H., Ruget, F., Nicoullaud, B., Gate, P., Devienne-Barret, F., Antonioletti, R., Durr, C., Richard, G., Beaudoin, N., Recous, S., Tayot, X., Plenet, D., Cellier, P., Machet, J. M., Meynard, J. M., and Delecolle, R.: STICS: a generic model for the simulation of crops and their water and nitrogen balances. I. Theory and parameterization applied to wheat and corn, Agronomie, 18, 311346, 1998. 
Brisson, N., Gary, C., Justes, E., Roche, R., Mary, B., Ripoche, D., Zimmer, D., Sierra, J., Bertuzzi, P., Burger, P., Bussiere, F., Cabidoche, Y. M., Cellier, P., Debaeke, P., Gaudillere, J. P., Henault, C., Maraux, F., Seguin, B., and Sinoquet, H.: An overview of the crop model STICS, Eur. J. Agronomy, 18, 309332, 2003.

Bsaibes, A., Courault, D., Baret, F., Weiss, M., Olioso, A., Jacob, F., Hagolle, O., Marloie, O., Bertrand, N., Desfond, V., and Kzemipour, F.: Albedo and LAI estimates from FORMOSAT-2 data for crop monitoring, Remote Sens. Environ., 113, 716-729, doi:10.1016/j.rse.2008.11.014, 2009.

Chern, J. S., Wua, M., and Lin, S: Lesson learned from FORMOSAT-2 mission operations, Acta Astronautica, 59, 344 350, 2006.

Combal, B., Baret, F., Weiss, M., Trubuil, A., Mace, D., Pragnere, A., Myneni, R., Knyazikhin, Y., and Wang, L.: Retrieval of canopy biophysical variables from bidirectional reflectance Using prior information to solve the ill-posed inverse problem, Remote Sens. Environ., 84, 1-15, 2003.

Courault, D., Bsaibes, A., Kpemlie, E., Hadria, R., Hagolle, O., Marloie, O., Hanocq, J. F., Olioso, A., Bertrand, N., and Desfonds, V.: Assessing the potentialities of FORMOSAT-2 data for water and crop monitoring at small regional scale in SouthEastern France, Sensors, 8, 3460-3481, doi:10.3390/s8053460, 2008.

Dedieu, G., Karnieli, A., Hagolle, O., Jeanjean, H., Cabot, F. Ferrier, P. and Yaniv, Y.: VENuS: A joint French - Israel Earth Observation scientific mission with High spatial and temporal resolution capabilities, edited by: Sobrino, J., Second Recent Advances in Quantitative Remote Sensing. Publicacions de la Universitat de València, 25-29 September 2006, Auditori de Torrent, Spain, 517-521, 2006.

Di Bella, C., Faivre, R., Ruget, F., Seguin, B., Guerif, M., Combal, B., Weiss, A., and Rebella, C.: Remote sensing capabilities to estimate pasture production in France, Int. J. Remote Sens., 25, 5359-5372, doi:10.1080/01431160410001719849, 2004.

Di Bella, C., Faivre, R., Ruget, F., and Seguin, B.: Using VEGETATION satellite data and the crop model STICS-Prairie to estimate pasture production at the national level in France, Phys. Chem. Earth, 30, 3-9, doi:10.1016/j.pce.2004.08.018, 2005.

Duchemin, B., Hadria, R., Erraki, S., Boulet, G., Maisongrande, P., Chehbouni, A., Escadafal, R., Ezzahar, J., Hoedjes, J. C. B., Kharrou, M. H., Khabba, S., Mougenot, B., Olioso, A., Rodriguez, J. C., and Simonneaux, V.: Monitoring wheat phenology and irrigation in Central Morocco: On the use of relationships between evapotranspiration, crops coefficients, leaf area index and remotely-sensed vegetation indices, Agric. Water Manage., 79, 1-27, doi:10.1016/j.agwat.2005.02.013, 2006.

Duru, M., Adam, M., Cruz, P., Martin, G., Ansquer, P., Ducouytieux, C., Jouany, C., Theau, J. P., and Viegas, J.: Modelling above-ground herbage mass for a wide range of grassland community types, Ecol. Model., 220, 209-225, doi:10.1016/j.ecolmodel.2008.09.015, 2009.

Evans, J. P.: 21st century climate change in the Middle East, Climatic Change, 92, 417-432, doi:10.1007/s10584-008-9438-5, 2009.

Guerif, M., Houles, V., and Baret, F.: Remote sensing and detection of nitrogen status in crops. Application to precise nitrogen fertilization, 4th International Symposium on Intelligent Infor- mation Technology in Agriculture, 26-29 October 2007 Beijing China Progress of Information Technology in Agriculture, 593601, 2007.

Hadria, R., Duchemin, B., Lahrouni, A., Khabba, S., Er-Raki, S., Dedieu, G., Chehbouni, A. G., and Olioso, A.: Monitoring of irrigated wheat in a semi-arid climate using crop modelling and remote sensing data: Impact of satellite revisit time frequency, Int. J. Remote Sens., 27, 1093-1117, doi:10.1080/01431160500382980, 2006.

Hagolle, O., Dedieu, G., Mougenot, B., Debaecker, V., Duchemin, B., and Meygret, A.: Correction of aerosol effects on multitemporal images acquired with constant viewing angles: Application to Formosat-2 images, Remote Sens. Environ., 112, 16891701, doi:10.1016/j.rse.2007.08.016, 2008.

Huete, A., Didan, K., Miura, T., Rodriguez, E. P., Gao, X., Ferreira, L. G.: Overview of the radiometric and biophysical performance of the MODIS vegetation indices, Remote Sens. Environ., 83, 195-213, 2002.

Jacob, F., Schmugge, T., Olioso, A., French, A., Courault, D., Ogawa, K., Petitcolin, F., Chehbouni, G., Pinheiro, A., and Privette, J.: Modeling and inversion in thermal infrared remote sensing over vegetated land surfaces, Advances in Land Remote Sensing: System, Modeling, Inversion and Application, 245291, 9th International Symposium on Physical Measurements and Signatures in Remote Sensing, Oct, 2005 Chinese Acad Sci, Inst Geog Sci \& Nat Resource Res Beijing, 2008.

Jones, J. W., Hoogenboom, G., Porter, C. H., Boote, K. J., Batchelor, W. D., Hunt, L. A., Wilkens, P. W., Singh, U., Gijsman, A. J., and Ritchie, J. T.: The DSSAT cropping system model, Eur. J. Agronomy, 18, 235-265, 2003.

Jongschaap, R. E. E.: Run-time calibration of simulation models by integrating remote sensing estimates of leaf area index and canopy nitrogen, Eur. J. Agronomy, 24, 316-324, 2006.

Launay, M. and Guerif, M.: Assimilating remote sensing data into a crop model to improve predictive performance for spatial applications, Agr. Ecosyst. Environ., 111, 321-339, doi:10.1016/j.agee.2005.06.005, 2005.

Launay, M., Brisson, N., Satger, S., Hauggaard-Nielsen, H., CorreHellou, G., Kasynova, E., Ruske, R., Jensen, E. S., and Gooding, M. J.: Exploring options for managing strategies for pea-barley intercropping using a modeling approach, Eur. J. Agronomy, 31, 85-98, doi:10.1016/j.eja.2009.04.002, 2009.

Mailhol, J. C. and Merot, A.: SPFC: a tool to improve water management and hay production in the Crau region, Irrig. Sci., 26, 289-302, doi:10.1007/s00271-007-0099-3, 2008.

Martimort, P., Berger, M., Carnicero, B., Del Bello, U., Fernandez, V., Gascon, F., Silvestrin, P., Spoto, F., Sy, O., Arino, O., Biasutti, R., Greco, B : Sentinel-2 - the optical high-resolution mission for GMES operational services, ISSN: 03764265, ESA Bulletin, 131, 18-23, 2007.

Merot, A., Bergez, J. E., Capillon, A., and Wery, J.: Analysing farming practices to develop a numerical, operational model of farmers' decision-making processes: An irrigated hay cropping system in France, Agric. Syst., 98, 108-118, doi:10.1016/j.agsy.2008.05.001, 2008a.

Merot, A., Wery, J., Isberie, C., and Charron, F.: Response of a plurispecific permanent grassland to border irrigation regulated by tensiometers, Eur. J. Agronomy, 28, 8-18, doi:10.1016/j.eja.2007.04.004, 2008b. 
Olioso, A., Inoue, Y., Ortega-Farias, S., Demarty, J., Wigneron, J. P., Braud, I., Jacob, F., Lecharpentier, P., Ottle, C., Calvet, J. C., and Brisson, N.: Future directions for advanced evapotranspiration modeling: assimilation of remote sensing data into crop simulation models and SVAT models, Irrig. Drainage Syst., 19, 377-412, 2005.

Pogacar, T. and Kajfez-Bogataj, L.: WOFOST: crop growth simulation model - 1st part, Acta Agriculturae Slovenica, 93, 231-243, 2009.

Ruget, F., Levrault, F., Tayot, X., Ripoche, D., and Ngueye, S.: Estimation of the water requirements of maize crops: regional or plot application, Vers une maitrise des impacts environnementaux de l'irrigation, Actes de l'atelier du PCSI, Montpellier, France, 2829 May 2002, 32, 10 pp., 2002.

Ruget, F., Novak, S., Granger, S.: Du modèle STICS au système ISOP pour estimer la production fourragère. Adaptation à la prairie, application spatialisée, Fourrages, 186, 241-256, 2006.

Ruget, F., Abdessemed, A., and Moreau, J. C.: Impact of global climate change scenarios on alfalfa production in France, Biodiversity and animal feed: future challenges for grassland production. Proceedings of the 22nd General Meeting of the European Grassland Federation, Uppsala, Sweden, 9-12 June 2008, 745747, 2008.

Ruget, F., Satger, S., Volaire, F., and Lelievre, F.: Modeling Tiller Density, Growth, and Yield of Mediterranean Perennial Grasslands with STICS, Crop Science, 49, 2379-2385, doi:10.2135/cropsci2009.06.0323, 2009.
Schapendonk, A. H. C. M., Stol, W., van Kraalingen, D. W. G., and Bouman, B. A. M.: LINGRA, a sink/source model to simulate grassland productivity in Europe, Eur. J. Agronomy, 9, 87-100, 1998.

Todisco, F. and Vergni, L.: Climatic changes in Central Italy and their potential effects on corn water consumption, Agr. Forest Meteorol., 148, 1-11, doi:10.1016/j.agrformet.2007.08.014, 2008.

Varella, H., Guerif, M., and Buis, S.: Global sensitivity analysis measures the quality of parameter estimation: The case of soil parameters and a crop model, Environ. Modell. Softw., 25, 310319, doi:10.1016/j.envsoft.2010.09.012, 2010.

Weiss, M., Baret, F., Leroy, M., Hautecoeur, O., Bacour, C., Prevot, L., and Bruguier, N.: Validation of neural net techniques to estimate canopy biophysical variables from remote sensing data, Agronomie, 22, 547-553, doi:10.1051/agro:2002036, 2002.

Weiss, M., Baret, F., Smith, G. J., Jonckheere, I., and Coppin, P.: Review of methods for in situ leaf area index (LAI) determination Part II. Estimation of LAI, errors and sampling, Agr. Forest Meteorol., 121, 37-53, doi:10.1016/j.agrformet.2003.08.001, 2004.

Wigneron, J. P., Calvet, J. C., Olioso, A., Chanzy, A., and Bertuzzi, P.: Estimating the root-zone soil moisture from the combined use of time series of surface soil moisture and SVAT modelling, Phys. Chem. Earth B, 24, 837-843, 1999. 